\title{
Evaluation of Allowable Bearing Capacity of Ayila Soil, South-West Nigeria
}

\section{*OZEBO, VC; IKUEMONISAN, FE}

\author{
Department of Physics, University of Lagos, Akoka, Nigeria \\ *Corresponding Author Email: cozebo@unilag.edu.ng
}

\begin{abstract}
Accurate determination of allowable bearing capacity of soil is key to geotechnical foundations design so as to prevent collapse of structures built on them. Allowable bearing capacity of the study location has been determined by shear wave velocity approach. The seismic data used in this study are the in-situ shear and compressional wave velocities values measured by a 12-channel signal enhancement seismograph. Three layers were detected by the method. Empirical formulations and mathematical relationship between seismic velocities and elastic parameters were used to evaluate the allowable bearing capacity and other parameters presented in Table 1 . Results show that allowable bearing capacity for layer 1 ranges from 123.56 to $173.54 \mathrm{kN} / \mathrm{m}^{2}$. Layer 2 ranges from 233.24 to $377.62 \mathrm{kN} / \mathrm{m}^{2}$, while layer 3 ranges from $437.62-616 \mathrm{kN} / \mathrm{m}^{2}$. It was observed that allowable bearing capacity increases with depth - a 13\% difference between layers 1 and 2 while between layer 2 and 3 there is a $22 \%$ difference. By comparison, the allowable bearing capacities evaluated in this study are in agreement with empirical values of allowable bearing capacity of soils proposed by other scholars. Findings show the study location is suitable for geotechnical foundation designs.
\end{abstract}

\section{DOI: $\underline{\text { https://dx.doi.org/10.4314/jasem.v23i4.7 }}$}

Copyright: Copyright $(92019$ Ozebo and Ikuemonisan. This is an open access article distributed under the Creative Commons Attribution License (CCL), which permits unrestricted use, distribution, and reproduction in any medium, provided the original work is properly cited.

Dates: Received: 25 March 2019; Revised: 19 April 2019; Accepted 22 April 2019

Keywords: Ayila, Shear wave velocity, Allowable bearing capacity, Coefficient of subgrade reaction

It is a common knowledge that foundation is the part of a structure that transmits the load of the structure to the underlying soil and rock. All structures constructed on land are supported on foundation. However, not every soil is suitable for geotechnical foundations design. Consequently, proper site investigation of soil must be carried out to prevent imminent loses and dangers associated with shear failure. According to Donal (2001), many methods abound for estimating time of occurrence of shear failure. The elastic theory is often used for evaluation of elastic or instantaneous settlement, though it gives approximate value, but the knowledge of shear wave velocity is most commonly used to measure the parameters of soil characterization (Keceli, 2012).

Accurate in-situ P-wave and S-wave velocity profiles are essential in geotechnical foundation designs. These parameters are used in both analysis of soil behavior under both static and dynamics loads where the elastic constants are input variables into the models defining the different state of deformations such as elastic, elasto-plastics and failure (Finn, 1984). Shear wave velocity approach is relatively easy to use and dependable because there is absolutely no need to consider the foundation size and depth since the influence of these parameters are inherently incorporated in the insitu measured shear wave *Corresponding Author Email: cozebo@ unilag.edu.ng velocity values; the bearing capacity of a single layer immediately under the foundation is directly determined as a one-step operation (Tezean et al, 2009). Furthermore, the in-situ measured shear wave velocity as a single index represents the real soil conditions much more effective and reliable than the laboratory tested shear strength parameters. It reflects the true photograph of the soil, containing the contribution of the void ratio, soil density, confining tresses, stress history, shear and compressive strength and geology age (Tezean et al, 2009). What is needed in construction of geotechnical foundation is low compressibility and compliance and high bearing capacity (Atat et al, 2013). In the light of above, this study is focused on evaluation of allowable bearing capacity, unit weight, elastic modulus, bulk modulus, and coefficient of subgrade reaction of Ayila, SouthWest Nigeria using P-wave and S-wave velocities approach to ascertain its suitability for geotechnical foundations design. Bearing capacity is the power of foundation to hold the forces from the engineering structure without undergoing shear failure or excessive settlement. It is the critical load per unit area at either the ground surface or at a certain depth below the ground surface, while allowable bearing capacity is the ratio of the ultimate resistance of the earth structure to the safety factor (Keceli, 2012). 


\section{MATERIALS AND METHODS}

Location of the Study Area: Figure 1 shows the study location. The study area is enclosed within the latitudes $6.54^{\circ}-6.58^{\circ} \mathrm{N}$ and longitudes $4.53^{\circ}-4.57^{\circ} \mathrm{E}$. It is located within the sedimentary formation area of Ogun Water Side local Government of Ogun State, South-West Nigeria.

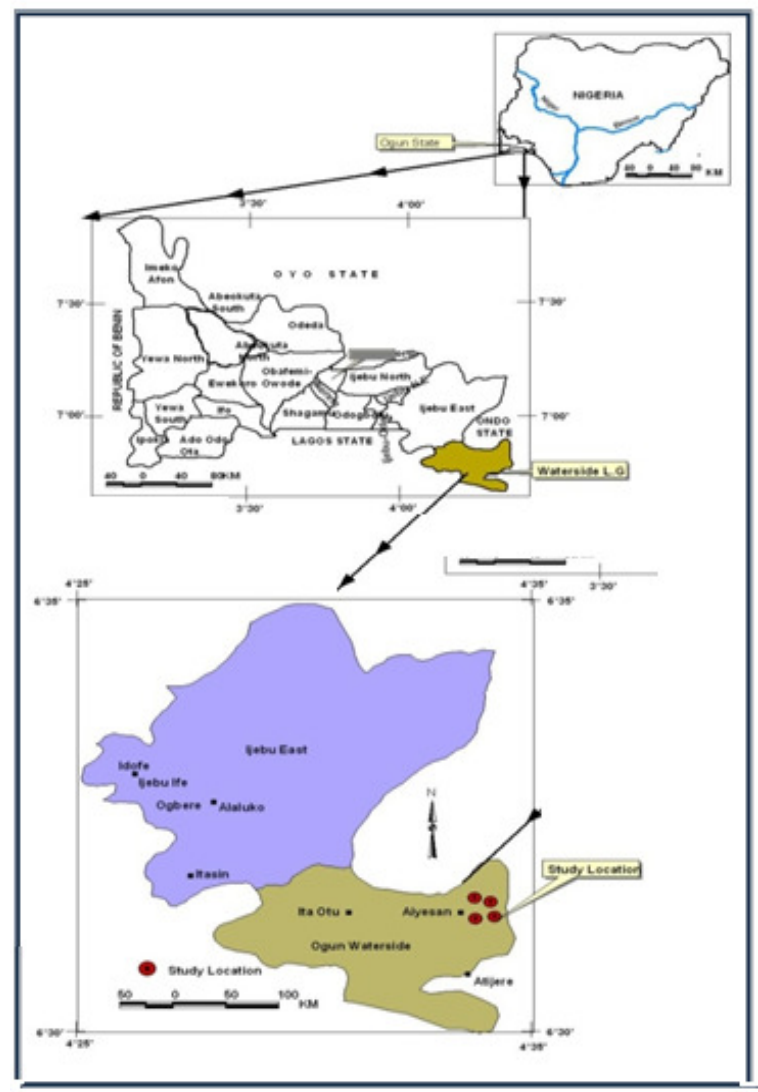

Fig 1. The study location

Seismic refraction study was carried out at Ayila with a view to ascertaining lithology composition of its overburden layers using $\mathrm{P}$-wave and $\mathrm{S}$-wave velocities. A 12-channel signal enhancement seismograph was used to record the traveltimes, and the propagation velocities of seismic waves through the layers were determined. Three layers were detected by the method, and the value of seismic wave velocities determined is adopted for the determination of geotechnical parameters in this study. In addition, empirical formulations proposed by various authors and mathematical relationship between seismic velocities and elastic parameters (Equation 1 to 13) are used to evaluate the allowable bearing capacity and other parameters presented in Table 1 .

Theoretical Background: In computations of bearing capacity for soil, the weight of the ground above the base level of the foundation is replaced by an equivalent load (Keceli, 2012). It was opined by Terzaghi and Peck (1967) that this substitution s.implifies the computations very considerably, the small error involved is unimportant and on the safe side. The equivalent load or the overburden pressure at foundation level is given as:

$$
q_{f}=\gamma d_{f}
$$

Where $\gamma$ is the unit weight of the ground, $d_{f}$ is the depth to foundation bottom from surface. The relationship between Shear Modulus $(\mu)$ and shear wave velocity $\left(V_{s}\right)$ is expressed as:

$$
\mu=\frac{\gamma V_{s}^{2}}{g}
$$

Where $\mathrm{g}$ is the acceleration due to free fall, $\gamma$ is the unit weight of the soil, $\rho$ is density and $V_{s}$ is shear wave velocity. The reciprocal of shear modulus is equal to compressibility and can be determined from it (Scott et al, 1968). The Unit Weight ( $\gamma$ ) is related to Pwave velocity as:

$$
\gamma=\gamma_{o}+0.002 V_{p}
$$

Where $V_{p}$ is compressional wave velocity.

Tezean et al (2009) determined the value of $\gamma_{o}$ (as the reference unit weight) in $\mathrm{kN} / \mathrm{m}^{3}$ to be 16 for loose, sandy and clayey soil and 17 for dense sand and gravel. Terzaghi and Peck (1967) and Bowles (1982) established the expressions for Subgrade Coefficient $\left(k_{s}\right)$, the ultimate bearing capacity, $q_{f}$ (the maximum pressure that a foundation soil can withstand without undergoing shear failure.) and allowable bearing pressure, $q_{a}$ (the maximum pressure the foundation soil is subjected to considering both shear failure and settlement.) as:

$$
\begin{aligned}
& k_{S}=4 \mathcal{W}_{S} \\
& q_{f}=\frac{k_{S}}{40} \\
& q_{a}=\frac{q_{f}}{n}
\end{aligned}
$$

Where $n$ is the factor of safety ( $n=4.0$ for soil).

Net ultimate Bearing Capacity $\left(q_{n}\right)$ is the maximum extra pressure (in addition to initial overburden pressure) that a foundation soil can withstand without undergoing shear failure.

$$
q_{n}=q_{f}=\gamma d
$$

Where $d$ is the depth to foundation bottom from ground level. 
Safe Bearing Capacity $\left(q_{s}\right)$ is the safe extra load the foundation soil is subjected to in addition to initial overburden pressure and can be expressed as:

$$
q_{s}=\frac{q_{n}}{n}+\gamma d
$$

In terms of shear wave velocity $\left(V_{S}\right)$, the allowable bearing capacity $\left(q_{a}\right)$ under shallow foundation in unit of $k P a$ may be obtained from the following empirical expression (Tezean et al, 2009):

$$
q_{a}=0.024 V_{s}
$$

Modulus of elasticity/Young's modulus $(E)$ : Modulus of elasticity is the ratio of tensile stress to tensile strain. Its reciprocal is equal to compliance (Scott et al, 1968). Modulus of elasticity can be expressed as:

$$
E=2 \mu(1+\sigma)
$$

Oedometric modulus $\left(E_{c}\right)$ can be expressed as:

$$
E_{c}=\frac{(1-\sigma) E}{(1+\sigma)(1-2 \sigma)}
$$

Where $\sigma$ is the Poisson's ratio which can be expressed as:

$$
\sigma=\left(\frac{\alpha-2}{2(\alpha-1)}\right)
$$

Where $\alpha=\left(\frac{V_{p}}{V_{s}}\right)^{2}$

Table 1. Seismic and elastic parameters of the study location

\begin{tabular}{llllllllllllll}
\multicolumn{10}{c}{ Table 1. Seismic and elastic parameters of the study location } \\
\hline SL & LY & Z1 & Z2 & Z3 & Z4 & Z5 & Z6 & Z7 & Z8 & Z9 & Z10 & Z11 & Z12 \\
\hline A & 1 & 803 & 305 & 17.60 & 0.11 & 0.16 & 6.93 & 0.41 & 0.09 & 1.34 & 5.36 & 2.14 & 0.47 \\
B & 2 & 1898 & 737 & 19.79 & 0.72 & 0.10 & 6.63 & 0.41 & 0.61 & 3.64 & 14.5 & 5.83 & 3.09 \\
& 3 & 3300 & 1091 & 22.60 & 2.51 & 2.74 & 9.14 & 0.43 & 2.23 & 6.16 & 24.6 & 9.86 & 7.89 \\
C & 1 & 702 & 284 & 17.40 & 0.08 & 0.14 & 6.10 & 0.40 & 0.07 & 1.23 & 4.94 & 1.97 & 0.40 \\
D & 2 & 1462 & 493 & 18.92 & 0.41 & 0.04 & 8.79 & 0.43 & 0.36 & 2.33 & 9.33 & 3.73 & 1.34 \\
& 3 & 2545 & 830 & 21.09 & 1.39 & 1.48 & 9.40 & 0.44 & 1.24 & 4.37 & 17.5 & 7.00 & 4.27 \\
E & 1 & 714 & 355 & 17.42 & 0.09 & 0.22 & 4.04 & 0.33 & 0.06 & 1.54 & 6.18 & 2.47 & 0.59 \\
F & 2 & 1522 & 697 & 19.04 & 0.45 & 0.09 & 4.76 & 0.36 & 0.35 & 3.31 & 13.2 & 5.31 & 2.58 \\
& 3 & 2817 & 1076 & 21.63 & 1.75 & 2.55 & 6.85 & 0.41 & 1.49 & 5.81 & 23.2 & 9.31 & 7.23 \\
G & 1 & 787 & 395 & 17.57 & 0.11 & 0.27 & 3.96 & 0.33 & 0.08 & 1.73 & 6.94 & 2.77 & 0.74 \\
H & 2 & 1488 & 796 & 18.97 & 0.42 & 0.12 & 3.49 & 0.29 & 0.30 & 3.77 & 15.1 & 6.04 & 3.18 \\
& 3 & 2457 & 1068 & 20.91 & 1.28 & 2.43 & 5.29 & 0.38 & 1.04 & 5.58 & 22.3 & 8.93 & 6.73 \\
I & 1 & 711 & 361 & 17.42 & 0.08 & 0.23 & 3.87 & 0.32 & 0.06 & 1.57 & 6.28 & 2.51 & 0.61 \\
J & 2 & 1442 & 614 & 18.88 & 0.40 & 0.07 & 5.51 & 0.38 & 0.32 & 2.89 & 11.5 & 4.63 & 2.01 \\
& 3 & 2672 & 943 & 21.34 & 1.55 & 1.93 & 8.02 & 0.42 & 1.36 & 5.03 & 20.1 & 8.05 & 5.53 \\
\hline
\end{tabular}

$S L=$ Sampling locations: $L Y=$ Layer; $A=$ Lat. $\left(6^{0} 33^{\prime} 44^{\prime \prime} N\right) ; B=$ Long $\left(4^{0} 32^{\prime} 34^{\prime \prime} E\right) ; C=\operatorname{Lat}\left(6^{\circ} 32^{\prime} 85^{\prime \prime} N\right) ; D=$ $\operatorname{Long}\left(4^{0} 31^{\prime 2} 23^{\prime \prime} E\right) ; E=\operatorname{Lat}\left(6^{0} 33^{\prime} 52^{\prime \prime} N\right) ; F=\operatorname{Long}\left(4^{0} 32^{\prime} 47^{\prime \prime} E\right) ; G=\operatorname{Lat}\left(6^{0} 32^{\prime} 78^{\prime \prime} N\right) ; H=\operatorname{Long}\left(4^{0} 32^{\prime} 79^{\prime \prime} E\right) ; \quad I=\operatorname{Lat}\left(6^{0} 32^{\prime} 12^{\prime \prime} N\right) ; J=$ Long(433'07" $E) ; Z 1=V_{p}(\mathrm{~m} / \mathrm{s}) ; Z 2=V_{s}(\mathrm{~m} / \mathrm{s}) ; Z 3=\gamma ; Z 4=E_{c} x 10^{7}\left(\mathrm{kN} / \mathrm{m}^{2}\right) ; Z 5=\mu x 10^{6}\left(\mathrm{kN} / \mathrm{m}^{2}\right) ; Z 6=\alpha ; Z 7=\sigma ; Z 8=K$ $x 10^{7}\left(\mathrm{kN} / \mathrm{m}^{2}\right) ; Z 9=q_{a} \times 10^{2}\left(\mathrm{kN} / \mathrm{m}^{2}\right) ; Z 10=q_{f} x 10^{2}\left(\mathrm{kN} / \mathrm{m}^{2}\right) ; Z 11=k_{s} x 10^{4}\left(\mathrm{kN} / \mathrm{m}^{2}\right) ; Z 12=E x 10^{6}\left(\mathrm{kN} / \mathrm{m}^{2}\right)$

\section{RESULTS AND DISCUSSION}

Table 1 shows Seismic and elastic parameters of the study location. The seismic data are the in-situ values measured on the field using a 12-channel seismic enhancement seismograph, while the elastic parameters are calculated using Equations 1 to 14 (i.e. empirical relations between seismic data and geotechnical parameters). The plots of allowable bearing capacity against shear wave velocity for the three layers are shown in Figure 2. Similarly, Figure 3 shows the plot of allowable bearing capacity against shear modulus for the three layers. The plots of allowable bearing capacity against shear modulus show linear relationship as shown in Equation 14 to 16.

$$
\begin{aligned}
& \text { Layer 1: } q_{a}=3.6 \mu \times 10^{-4}+73 \\
& \text { Layer 2: } q_{a}=1.9 \mu \times 10^{-4}+150 \\
& \text { Layer 3: } q_{a}=1.4 \mu \times 10^{-4}+240
\end{aligned}
$$

The gradient of a plot of allowable bearing capacity against shear modulus is equal to deformation constant (Atat et al, 2013). The magnitudes of deformation constants are; Layer 1: $3.6 \times 10^{-4}$; Layer 2: $1.9 \times 10^{-4}$ and Layer $3: 1.4 \times 10^{-4}$ respectively. Comparing the magnitude of deformation constants with their respective layer's allowable bearing capacity, layer 3 being the layer with the lowest deformation constant has the greatest allowable bearing capacity when compared to layers 1 and 2. Since allowable bearing capacity increases with depth (Atat et al, 2013), it is 
therefore expected that the value of elastic deformation constant for layer 3 is higher.
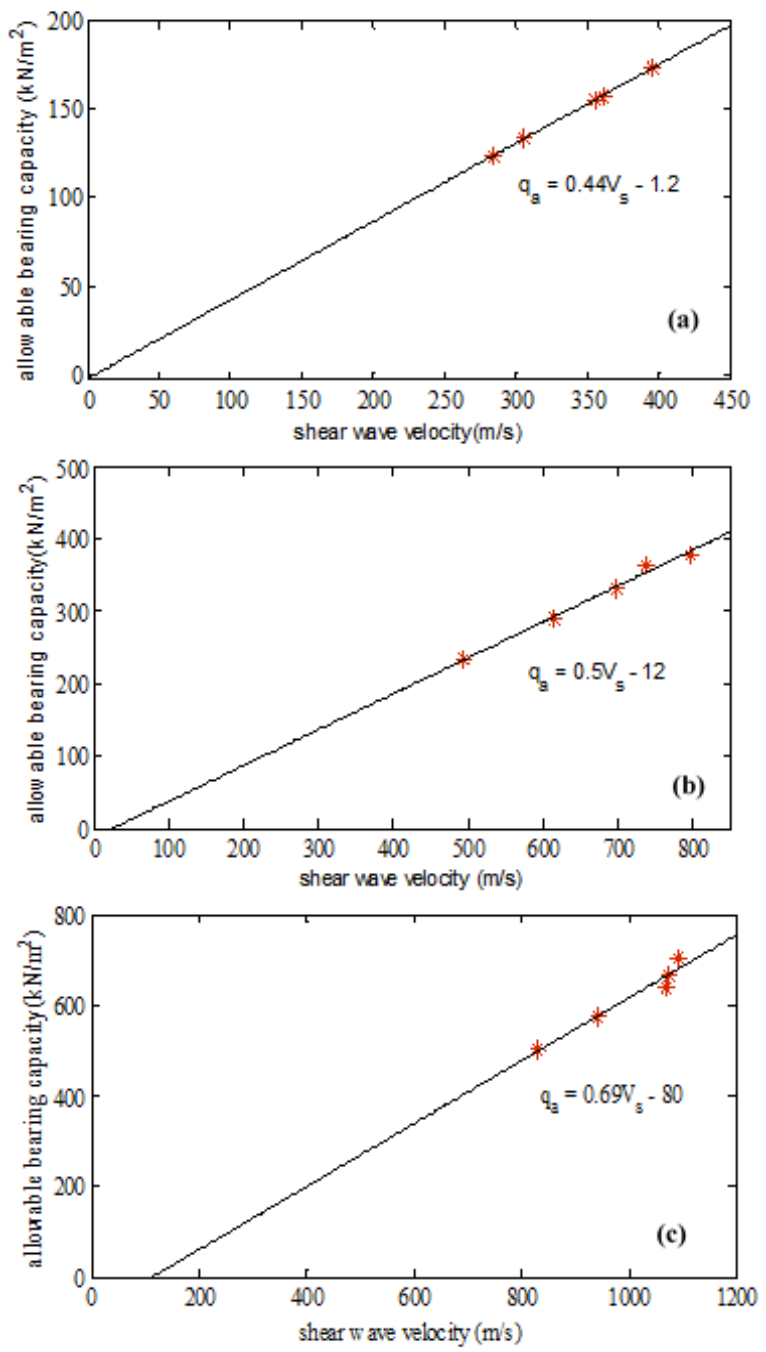

Fig 2. (a) - A plot of allowable bearing capacity against shear wave velocity for layer 1; (b) - A plot of allowable bearing capacity against shear wave velocity for layer 2; (c) - A plot of allowable bearing capacity against shear wave velocity layer 3 .

Consequently, the effect of intercept value on the allowable bearing capacity axis is significant. This effect will be considered in our subsequent study.

The plot of allowable bearing capacity against shear wave velocity also show a linear relationship as shown in Equations 17 to 19.

$$
\begin{aligned}
& \text { Layer 1: } q_{a}=0.44 v_{s}-1.2 \\
& \text { Layer 2: } q_{a}=0.5 v_{s}-12 \\
& \text { Layer 3: } q_{a}=0.61 v_{s}-70
\end{aligned}
$$

According to Atat et al (2013), the gradient of a plot of allowable bearing capacity against shear wave velocity is the impulse producing deformability of foundation layer per cubic meter, expressed in $\mathrm{Ns} / \mathrm{m}^{3}$
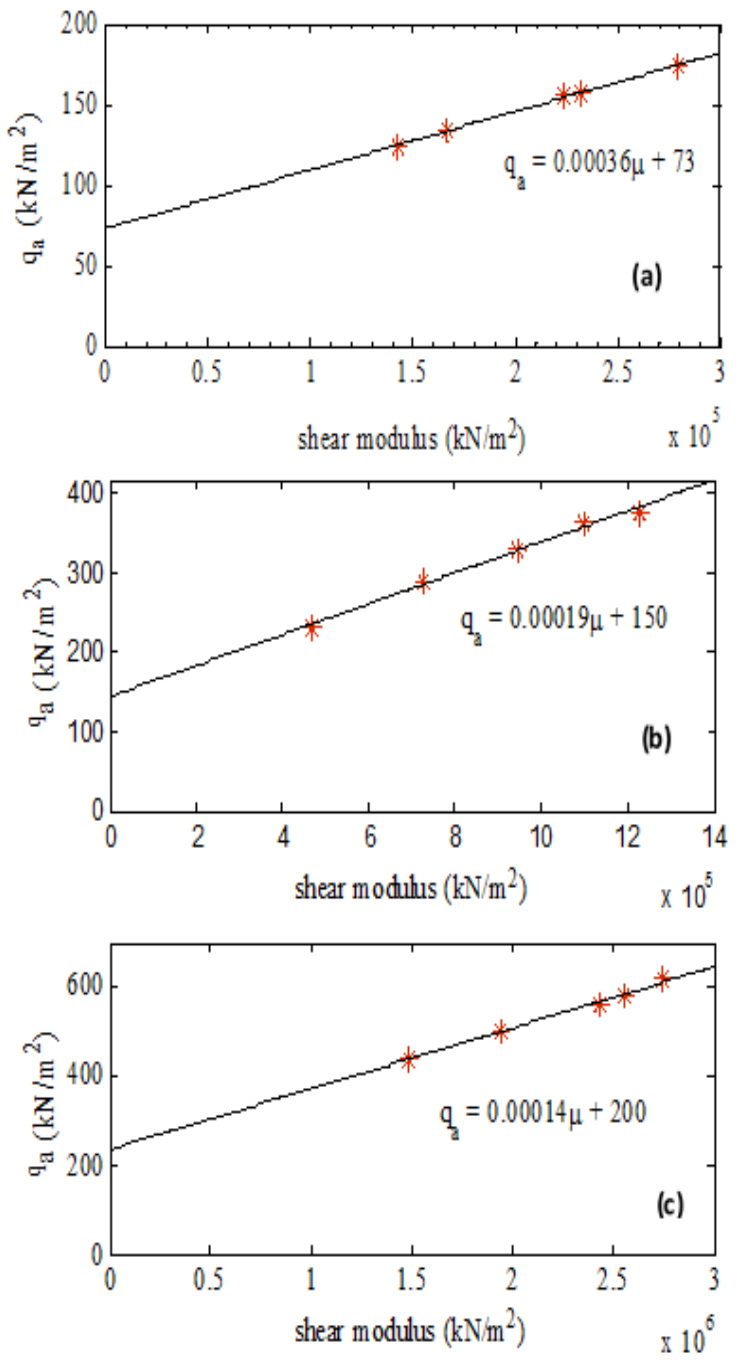

Fig 3. (a) - A plot of allowable bearing capacity against shear modulus for layer 1; (b) - A plot of allowable bearing capacity against shear modulus for layer 2; (c) - A plot of allowable bearing capacity against shear modulus for layer 3 .

For layer 1, the gradient is $0.44 N \mathrm{~s} / \mathrm{m}^{3}$, layer 2 is $0.5 \mathrm{Ns} / \mathrm{m}^{3}$ and layer 3 is $0.61 \mathrm{Ns} / \mathrm{m}^{3}$. It is observed that there are variations in the gradients for the three layers. The differences between layers 1 and 2 and layer 2 and 3 respectively are $13 \%$ and $22 \%$. These variations show that allowable bearing capacity of the study area increase with depth. Layer 1 has allowable bearing capacity ranging between 123.56 $173.54 \mathrm{kN} / \mathrm{m}^{2}$ with average value of $148.65 \mathrm{kN} / \mathrm{m}^{2}$. Layer 2 has allowable bearing capacity ranging between $233.24-377.62 \mathrm{kN} / \mathrm{m}^{2}$ with average value of $319.46 \mathrm{kN} / \mathrm{m}^{2}$ and layer 3 allowable bearing capacity ranging from $437.62-616 \mathrm{kN} / \mathrm{m}^{2}$ with an average value of $539.51 \mathrm{kN} / \mathrm{m}^{2}$. 
According to [9], the range of allowable bearing capacity for soil type: Medium stiff clay with shear wave velocities $(200-350) \mathrm{m} / \mathrm{s}$ is $(75-150) \mathrm{kN} / \mathrm{m}^{2}$ : Very stiff clay boulders with shear wave velocities $(450-800) \mathrm{m} / \mathrm{s}$ is $(200-350) \mathrm{kN} / \mathrm{m}^{2}$ : Very hard clays with shear wave velocity $(800-1200) \mathrm{m} / \mathrm{s}$ is $(350-500)$ $\mathrm{kN} / \mathrm{m}^{2}$. Comparing these with our results the three layers are suitable for engineering constructions. The results also show conformity with the presumptive allowable bearing capacity put forward by Brown (1992) and (Keceli, 2012).

Conclusion: Allowable bearing capacity as well as elastic parameters of Ayila has been determined using in-situ seismic data measured by 12-channel seismic enhancement seismograph and related empirical formulations. Comparing the range of values of allowable bearing capacities in literatures with the computed values for the three layers, it is evident that layers 1, 2 and 3 are all suitable for shallow geotechnical foundation designs. However, since bearing capacity increases with depth, and top soil (layer 1) is open to erosion and degradation, layers 2 and 3 are therefore more suitable for geotechnical foundation designs.

\section{REFERENCES}

Atat, JG; Akpabio, IO; George, NJ (2013). Allowable Bearing Capacity for Shallow Foundation in Eket Local government Area, Akwa Ibom State, Southern Nigeria. Inter. J.Geosci.4: 1491-1500.

Bowles, JE. (1982). Foundation Analysis and Design. $3^{\text {rd }}$ Ed. MeGraw-Hill Book Campany, New York.
Brown, DW (1992). Engineering and Design Bearing Capacity of Soil, (Engineer Manual) Department of the Army, U.S. Army Corps of Engineers, Washington, DC 20314-1000

Donal, P C (2001). Foundation Design: Principles and Practices: $2^{\text {nd }} E d$. Prentice Hall. ISBN-10: 0- 13589706-8.

Finn, WDL. (1984). Dynamic Response Analysis of Soil in Engineering Practice, Machanis of Engineering mateas, John Wiley \& Son Ltd. London.

Keceli, AD (2012). Soil Parameters which can be determined by Seismic Velocities. Jeofizik 16:1929.

Scott, JH; Lee, FT; Carrol, RD; Robinson, CS (1968). The Relationship of geophysical measurement to Engineering and Construction Parameters in the Straight Creek Tunnel Pilot Boring Colorado. Inter. J. Rock Mech. Min. Sci. Geomach. 5 (1): 130 .

Terzaghi, K; Peck, RB (1967). Soil Mechanics in Engineering Practice, $2^{\text {nd }}$ ed., John Wley \& Sons. London.

Tezcan, SS; Ozdemir, Z; Keceli, A (2009). Seismic Technique to Determine the Allowable Bearing pressure for Shallow Foundations in Soil and Rocks. Acta Geophysica 57 (2): 400 - 412

Tezcan, SS; Ozdemir, Z; Keceli, A (2006). Allowable bearing capacity of Shallow Foundations Based on Shear Wave Velocity. Geotech. Geo-environ. Engineer. 24, (1): 203-218. 